\title{
AS PÓS-GRADUAÇÕES DO IPHAN COMO TERMÔMETRO DA GESTÃO DO PATRIMÔNIO ARQUEOLÓGICO
}

\author{
Alejandra Saladino ${ }^{1}$ \\ Luana Campos ${ }^{2}$ \\ Lia Motta ${ }^{3}$ \\ Juliana Ferreira Sorgine ${ }^{4}$
}

\section{RESUMO}

A partir da observação dos perfis de vagas de bolsa de estudo propostos por unidades do IPHAN à Coordenação do Mestrado Profissional em Preservação do Patrimônio Cultural da própria instituição, para formulação dos editais de seleção do curso, foi será apresentada uma reflexão sobre as especificidades e os desafios da formação e atuação dos agentes voltados para a gestão do patrimônio arqueológico. A análise desses perfis de vaga e das atividades práticas supervisionadas oferecidas pelas unidades institucionais, do corpo discente selecionado, somados à reflexão sobre os objetivos do curso, conteúdo programático e recursos metodológicos aplicados na disciplina do Mestrado intitulada "Patrimônio Arqueológico: legislação e pesquisa", confirmam a vocação transdisciplinar da gestão do patrimônio arqueológico e o desafio de adequar os tópicos específicos da Arqueologia para torná-los acessíveis e aplicáveis por parte dos recém-formados agentes patrimoniais cultural nos seus postos de atuação.

PALAVRAS-CHAVE: formação, gestão, patrimônio arqueológico, IPHAN.

\section{ABSTRACT}

As from the observation of the vacancies of students offered by IPHAN units to the Coordination of the Professional Master in Preservation of Cultural Heritage of the institution itself, we aim to reflect on the specificities and challenges of the formation and performance of agents focused on the management of archaeological heritage. The analysis of the

\footnotetext{
${ }^{1}$ Museóloga (UNIRIO), especialista em Conservação de Bens Culturais Móveis (EBA/UFRJ), mestre em Arqueologia (MN/UFRJ) e Memória Social (UNIRIO), doutora em Ciências Sociais (UERJ), Professora Associada do Departamento de Estudos e Processos Museológicos (DEPM/CCHS/UNIRIO) e docente permanente do Mestrado Profissional em Preservação do Patrimônio Cultural do IPHAN.

2 Historiadora (UFMS), Mestre em Arqueologia Pré-histórica e Arte Rupestre (UTAD/Portugal), Doutora em "Quaternário, materiais e culturas" (UTAD/Portugal) com reconhecimento pelo Doutorado em Arqueologia da UFPE. Professora "recém-doutora" do Mestrado Profissional em Preservação do Patrimônio Cultual do IPHAN.
}

${ }^{3}$ Arquiteta do Instituto do Patrimônio Histórico e Artístico Nacional - IPHAN, especialista em Conservação e Restauração de Sítios e Monumentos Históricos, mestre em Memória Social (UNIRIO), doutora em Urbanismo (UFRJ) e docente permanente do Mestrado Profissional em Preservação do Patrimônio Cultual do IPHAN.

${ }^{4}$ Historiadora (UFRJ), mestre em História Social (UFRJ), historiadora do Instituto do Patrimônio Histórico e Artístico Nacional, lotada no Centro Lucio Costa: Escola do Patrimônio e docente permanente e vice-coordenadora do Mestrado Profissional em Preservação do Patrimônio Cultural do IPHAN.

\begin{tabular}{|l|l|l|l|l|l|l|}
\hline (C) Rev. Arqueologia Pública & Campinas, SP & v.13 & n.2 & p.146 & 2019 & ISSN 2237-8294 \\
\hline
\end{tabular}


demands presented to the Master, the supervised practical activities offered by the institutional units, the selected student body and the reflection on the course objectives, syllabus and methodological resources applied in the Master's discipline, entitled "Archaeological Heritage: legislation and research", confirm the transdisciplinary vocation of archaeological heritage management and the challenge of adapting the specific topics of archeology to make them accessible and applicable by the newly formed cultural heritage agents in their positions.

KEYWORDS: qualification, management, archaeological heritage, IPHAN.

\section{RESUMEN}

Teniendo en cuenta las peticiones presentadas por el IPHAN a la coordinación del Máster Profesional en Preservación del Patrimonio Cultural, pretendemos relfexionar sobre las especificidades y los retos de la formación y actuación de agentes volcados para la gestión del patrimonio arqueológico. El análisis de las peticiones, del conjunto de professores y de estudiantes del Máster y la reflexión sobre los os objetivos, contenidos y metodologias aplicadas en las aulas de "Patrimonio Arqueológico: legislación e investigación", confirman la vocación del campo del patrimonio para la transdisciplinairidad y la necesidad de adaptar los temas específicos de la Arqueología para hacerlos mas accesibles y manejables por los titulados em el Máster em sus distintos locales de trabajo.

PALABRAS CLAVE: formación, gestión, patrimonio arqueológico, IPHAN.

\section{INTRODUÇÃO}

A questão central de nossa reflexão é encontrar algumas pistas sobre as especificidades da gestão do patrimônio arqueológico de competência da instituição responsável pela sua preservação: o Instituto do Patrimônio Histórico e Artístico Nacional IPHAN. Partimos do princípio de que, embora as ações sobre o patrimônio arqueológico sejam de competência dos arqueólogos, estando hoje prevista na Lei de regulamentação da profissão no 13.653 de 2018, algumas ações da gestão desses bens se adéquam ao compartilhamento com outras áreas de conhecimento, diante do caráter transdisciplinar dessa gestão. Isso vem sendo demonstrado nas estratégias usadas pelo IPHAN, que serão analisadas a partir dos perfis de vagas de bolsa de estudo propostos pelas unidades da instituição aos seus programas de pós-graduação, inicialmente a Especialização em Patrimônio Cultural e atualmente o Mestrado Profissional em Preservação do Patrimônio Cultural para a formulação dos seus editais de seleção. Destarte, objetivamos refletir sobre as especificidades e os desafios da formação e atuação desses agentes voltados para as ações de gestão dos bens arqueológicos. 
Os perfis de vaga de bolsa propostos pelas unidades do IPHAN são indicativos para um diagnóstico das necessidades e problemas enfrentados pelo órgão e das carências de uma formação que habilite profissionais a participarem da gestão de preservação de bens arqueológicos, conforme se busca contemplar no Mestrado da instituição.

O Mestrado do IPHAN, teve origem no Programa de Especialização em Patrimônio do IPHAN/UNESCO, criado em 2004, com ingresso da primeira turma em 2005. Em 2011, obteve a recomendação do Conselho Técnico-Científico da Educação Superior da CAPES (Coordenação de Aperfeiçoamento de Pessoal de Nível Superior, do Ministério da Educação) para seu funcionamento como um mestrado profissional e, em 2012, o Mestrado foi reconhecido pelo Ministério de Educação, podendo titular como mestres em preservação do patrimônio cultural os alunos que concluírem o curso.

Desde que era um Programa de Especialização, o objetivo da pós-graduação do IPHAN sempre foi propiciar uma formação interdisciplinar para atuação de profissionais de diversas áreas de conhecimento no campo da preservação do patrimônio cultural, abordando aspectos sociais, históricos, jurídicos e tecnológicos aplicados ao campo. Para isso, as turmas são compostas através de editais públicos de seleção de dois tipos: um primeiro, em que há o oferecimento de vagas pelas unidades que compõem a estrutura do IPHAN (departamentos da área central de direção, superintendências, escritórios técnicos e unidades especiais), que dão aos alunos a oportunidade de um contato cotidiano prático com diferentes abordagens da preservação do patrimônio cultural, como bolsistas externos que se inserem na estrutura do IPHAN. E um segundo tipo de edital, que se destina à seleção de alunos servidores públicos, da instituição e de fora dela ${ }^{5}$, em que estes propõem os temas de seu interesse a serem desenvolvidos no mestrado, pensados a partir de práticas profissionais relacionadas à preservação cultural. Baseada em grande medida no aprendizado obtido da vivência dessas práticas profissionais, a formação oferecida pelo Mestrado Profissional do IPHAN inclui módulos de aulas e orientações de pesquisas, dedicados ao aprofundamento dos conteúdos teórico-metodológicos necessários à produção de pensamento crítico sobre a preservação cultural, que são organizados pela Coordenação do programa, hoje situada na estrutura do Centro Lucio Costa: Escola do Patrimônio do IPHAN, no Rio de Janeiro.

${ }^{5}$ Além dos editais do Mestrado destinados aos servidores públicos do IPHAN, publicados desde 2012, a partir de 2018 foram abertas vagas para servidores de municípios e distrito federal com sítios declarados patrimônio mundial pela UNESCO e para servidores públicos federais de instituições que atuam em áreas de preservação de bens culturais ou afins.

\begin{tabular}{|l|l|l|l|}
\hline (c) Rev. Arqueologia Pública & Campinas, SP & v.13 & n.2
\end{tabular}

p. 148

2019 ISSN 2237-8294 
Cabe aqui um breve esclarecimento sobre a localização da sede do Mestrado na cidade do Rio de Janeiro, pois, esta corresponde a parte importante da formação do aluno, visto que a cidade agrega em seu território o maior número de bens acautelados do país permitindo aos alunos uma aproximação com essa diversidade durante os módulos de aula, assim como o acesso a arquivos e bibliotecas importantes para o tema da preservação, entre esses o arquivo e a biblioteca mais antigos do IPHAN.

A diversidade de temas e bens abordados no curso, assim como dos profissionais envolvidos nessa formação, vêm ao encontro do que define a Constituição Federal de 1988, ao adotar uma concepção ampla de patrimônio, como sendo bens "portadores de referência à identidade, à ação e à memória dos diferentes grupos formadores da sociedade brasileira" (BRASIL, 1988). Trata-se de ideia ampla que requer recortes e a interação com a sociedade, a respeito dos valores a serem protegidos pelo poder público. Assim, embora reconhecendo que o patrimônio cultural tenha um caráter milenar, podendo ser considerado uma categoria de pensamento, aqui será abordado como uma invenção moderna que se tornou objeto de políticas públicas (GONÇALVES, 2009), destacando as especificidades da gestão dos bens arqueológicos.

Nesse sentido, optamos por nos concentrar na dimensão jurídico-legal do patrimônio cultural, em detrimento de sua percepção enquanto categoria de pensamento. Partimos também do conceito de instituição à luz do "institucionalismo histórico", a partir do qual é possível compreender o termo como o conjunto complexo de convenções, normas, enquadramentos e dispositivos legais, além da mais variada gama de agentes sociais, atuando nos campos político, econômico, jurídico-legal e social. E nos debruçamos sobre um tipo de patrimônio, o arqueológico.

De acordo como Art. 1ำ da Carta de Lausanne (ICOMOS, 1990), o patrimônio arqueológico:

[...] compreende a porção do patrimônio material para a qual os métodos da Arqueologia fornecem os conhecimentos primários. Engloba todos os vestígios da existência humana e interessa todos os lugares onde há indícios de atividades humanas, não importando quais sejam elas; estruturas e vestígios abandonados de todo tipo, na superfície, no subsolo ou sob as águas, assim como o material a eles associados. 
Desse modo, é claramente reconhecível a primazia da perspectiva científica (arqueológica) sobre a definição desta categoria de bem cultural. Em outras palavras, é a/o arqueóloga/o, por meio da aplicação dos conceitos teórico-metodológicos, quem define o que é patrimônio arqueológico. Por outro lado, quem é o responsável pela sua gestão?

Em um passado recente, os cursos de Arqueologia no Brasil, nos níveis de graduação e de pós-graduação, se multiplicaram devido às demandas sociais, muitas delas diretamente associadas ao Programa de Aceleração do Crescimento (PAC) ${ }^{6}$, cujas ações exigiram o desenvolvimento de pesquisas para liberar a execução de obras incentivadas ou executadas por incentivo do governo brasileiro. Diversos estudos, reunidos em um dossiê por Sibeli Vianna, Marcia Bezerra e Jorge Eremites (2015) ${ }^{7}$, indicam, entretanto, que a formação em Arqueologia, além de não ter matriz curricular comum, não prioriza a gestão dos bens arqueológicos. De modo geral, priorizam, por exemplo, técnicas de escavação, análises químicas, análise dos artefatos e o salvamento, indo até o depósito de material nas instituições de guarda. Após essas etapas de pesquisa, são poucas as propostas de abordagem dos remanescentes dos sítios e de acompanhamento dos materiais resgatados, o que está sendo entendido aqui como a última etapa do processo de gestão - iniciado, no nosso entender ${ }^{8}$, desde as ações de identificação dos sítios arqueológicos e da concepção de projetos -, que deveria também ser parte da formação dos arqueólogos.

Assim sendo, quem pode assumir a gestão desses bens culturais, não renováveis, que exigem a preservação por meio documental e do vínculo com o contexto (caso contrário, seu valor informacional fica definitivamente comprometido)? Bens esses que, em grande parte, estão associados às memórias exiladas das sociedades pretéritas e marginalizadas, ao que Cristina Bruno se refere como estratigrafia do abandono, "construída ao longo da historicidade da cultura brasileira" (BRUNO, 2018:115).

A metodologia aplicada para fundamentar nossos argumentos e reflexões a respeito dos indicativos que o Mestrado do IPHAN nos proporciona para compreender as

\footnotetext{
${ }^{6}$ Segundo informações do site do então Ministério do Planejamento, o PAC foi um programa criado em 2007 pelo Governo Federal Brasileiro, durante a gestão do Presidente Luís Inácio Lula da Silva, para promover a retomada do planejamento e execução de grandes obras de infraestrutura social, urbana, logística e energética do país. (BRASIL,2007)

${ }^{7}$ Cabe lembrar ainda o artigo de Marcia Bezerra (2008).

8 Ver Portaria $n^{0} 375 / 2018$ do IPHAN.

(C) Rev. Arqueologia Pública

Campinas, SP

\begin{tabular}{l|l|l} 
v.13 & $n .2$ \\
\hline
\end{tabular}

p. 150

2019

ISSN 2237-8294
} 
necessidades e problemas da gestão do patrimônio arqueológico, foi a coleta e análise de dados sobre as vagas oferecidas pelas unidades da instituição, apresentadas em quatro partes. Na primeira, apresentamos um brevíssimo panorama sobre o lugar da Arqueologia no IPHAN, visto que há diversos estudos sobre o tema (SALADINO, 2010; STANCHI, 2017). Em seguida, expomos um perfil do Mestrado em Preservação do Patrimônio Cultural do IPHAN e os resultados da análise das necessidades do IPHAN para a gestão do patrimônio arqueológico apresentadas no oferecimento de vagas à pós-graduação em tela. $\mathrm{Na}$ terceira parte, tratamos da disciplina obrigatória "Patrimônio Arqueológico: legislação e pesquisa" e refletimos sobre os desafios de ordem conceitual e metodológica para adequála ao corpo discente do Mestrado. Por fim, sistematizamos os desafios da formação para a gestão do patrimônio arqueológico, considerando a complexidade e as especificidades da gestão do patrimônio cultural no que concerne à inter e à multidisciplinaridade inerentes à área da Arqueologia.

\section{ARQUEOLOGIA E O IPHAN: UM BREVE PANORAMA}

Embora tenham sido realizadas pesquisas arqueológicas no Brasil desde meados do século XIX (FUNARI, 2013), as primeiras políticas de preservação do patrimônio arqueológico vêm com o Estado Novo Varguista, decorrentes da busca pela criação de uma identidade nacional ${ }^{9}$. Nesse contexto, os bens arqueológicos foram tratados no Art. $1^{\circ}$ do Decreto-Lei n 25/1937, como parte do "patrimônio histórico e artístico nacional" tendo em vista o "excepcional valor arqueológico". A proteção se dava então pela inscrição no primeiro livro do Tombo, denominado Etnográfico, Arqueológico e Paisagístico, reservado às coisas pertencentes às categorias de arte arqueológica, etnografia, ameríndia e popular.

Apesar da presença do patrimônio arqueológico como passível de reconhecimento institucional pelo instrumento administrativo do tombamento, a necessidade crescente de ações mais urgentes na proteção dos sítios e bens arqueológicos fez com que, em 1961, um grupo de pesquisadores e ativistas da valorização e preservação dos bens arqueológicos, dentre os quais destacamos Loureiro Fernandes, Luiz de Castro Faria e Paulo Duarte, conseguisse a aprovação da Lei no 3.924, que dispõe sobre a proteção dos monumentos arqueológicos e pré-históricos.

${ }^{9}$ A esse respeito, ver CHUVA (2003).

\begin{tabular}{|l|l|l|l|l|l|l|} 
(C) Rev. Arqueologia Pública & Campinas, SP & v.13 & n.2 & p.151 & 2019 & ISSN 2237-8294
\end{tabular}


De acordo com o Art. $1^{\circ}$ da Lei $n^{\circ} 3.924 / 1961$ "os monumentos arqueológicos ou préhistóricos de qualquer natureza existentes no território nacional e todos os elementos que neles se encontram ficam sob a guarda e proteção do Poder Público", sendo responsabilidade do IPHAN a elaboração e execução de políticas públicas que garantam essa guarda e proteção, principalmente por meio da manutenção de um cadastro dos sítios arqueológicos.

Embora contando com uma lei dedicada à proteção dos bens arqueológicos desde o início da década de 1960, somente na década de 1970 foi criado o primeiro curso de graduação para arqueólogos no Brasil, inicialmente vinculado às Faculdades Rondon, depois à Faculdade Estácio de Sá, no Rio de Janeiro (BEZERRA, 2008), sendo desativado no final da década de 1990. Ou seja, a formação de quadros de profissionais para atuar na pesquisa e na preservação do patrimônio arqueológico era insuficiente para a dimensão e a importância da Arqueologia brasileira, ainda em processo de mensuração.

Para o IPHAN, como instituição responsável pela preservação do patrimônio cultural, a solução foi estabelecer cooperações com as instituições de pesquisa existentes, em particular com o Museu Nacional do Rio de Janeiro (SALADINO, 2010). Essa solução se mostrou insuficiente, pois o crescimento exponencial das descobertas arqueológicas e as investidas dos empreendimentos sobre as jazidas arqueológicas eram muito superiores à capacidade de acompanhamento dos 'delegados' ${ }^{\prime 0}$. Esse quadro de desamparo técnico na salvaguarda e preservação do patrimônio arqueológico se agrava com a assinatura da Resolução do Conselho Nacional do Meio Ambiente (CONAMA/IBAMA) no 001/1986, que dispõe sobre os critérios básicos e as diretrizes gerais para uso e implementação da Avaliação de Impacto Ambiental, incluindo os estudos de impactos o meio socioeconômico, com destaque para os sítios e monumentos arqueológicos.

A parceria realizada entre o IPHAN e o IBAMA na preservação do patrimônio cultural foi um dos maiores avanços para o cumprimento da legislação vigente. Contudo, as instituições não estavam devidamente preparadas para lidar com o volume de trabalho que surgiria, sendo apenas em 1988 publicada a portaria que estabelece os procedimentos

10 Termo utilizado para os profissionais das instituições de pesquisa que atuavam pelo IPHAN na proteção do patrimônio arqueológico (SILVA, 1996).

\begin{tabular}{|l|l|l|l|l|l|l|}
\hline (C) Rev. Arqueologia Pública & Campinas, SP & v.13 & n.2 & p.152 & 2019 & ISSN 2237-8294 \\
\hline
\end{tabular}


mínimos necessários às comunicações prévias, às permissões e autorizações de pesquisa, tal como consta na Portaria IPHAN no 07/1988.

Na década de 1990, quando o IPHAN deu início aos seus procedimentos de informatização de dados, foi criado o Sistema de Gerenciamento do Patrimônio Arqueológico (SGPA), em 1997, e o Cadastro Nacional de Sítios Arqueológicos (CNSA) por meio da edição da Portaria no 241 de 1998, para o registro e atualização dos dados a respeito dos sítios ${ }^{11}$. Apenas em 2002 é assinada a Portaria IPHAN nำ 230/2002 que estabelece as etapas de pesquisas para a obtenção das licenças prévias, de instalação e de operação dos empreendimentos.

De 2000 a 2018, de acordo com a base de dados do IPHAN (Gráfico 1), o número de portarias de autorização de pesquisa arqueológica aumentou quase $2000 \%$, o que tornou os trabalhos de preservação de bens arqueológicos uma questão de grande monta para a instituição.

Gráfico 1. Número de autorização de pesquisa emitidas pelo IPHAN

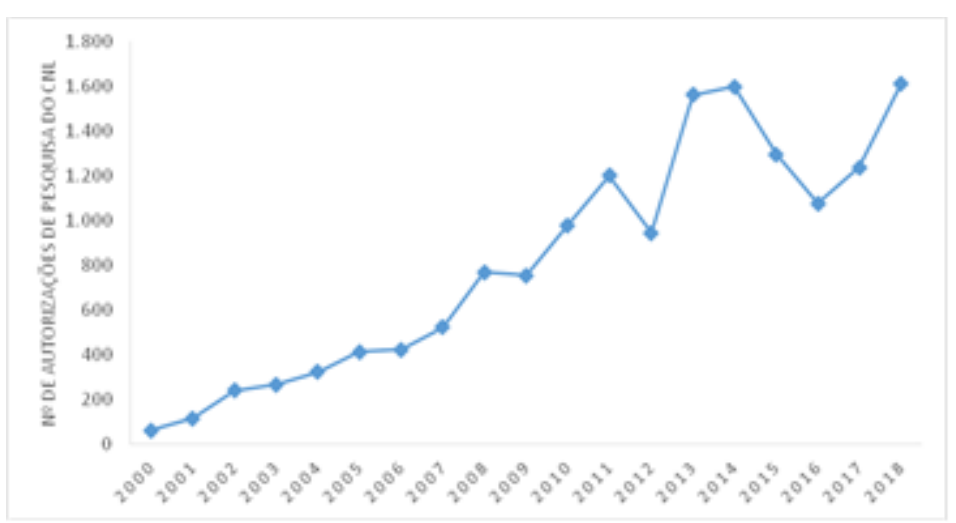

Fonte: IPHAN/2019.

Isso se refletiu nos investimentos em concursos entre os anos de 2005 e 2018, para contratação de pessoal para atuar na Arqueologia, totalizando 205 profissionais, entre servidores permanentes e temporários, conforme tabela abaixo (Tabela 01).

11 O IPHAN contava até então com um sistema de fichamentos em papel: o Cadastro de Sítios Arqueológicos do Brasil.

\begin{tabular}{|l|l|l|l|l|l|l|}
\hline (C) Rev. Arqueologia Pública & Campinas, SP & v.13 & n.2 & p.153 & 2019 & ISSN 2237-8294 \\
\hline
\end{tabular}


Tabela 01. Concursos realizados pelo IPHAN área de arqueologia

\begin{tabular}{|c|c|c|c|}
\hline Anos & $\begin{array}{l}\text { N. de } \\
\text { vagas }\end{array}$ & Enquadramento funcional & Fonte \\
\hline 2005 & 22 & Efetivo & $\begin{array}{l}\underline{\text { https://www.pciconcursos.com.br/concurso/iphan- }} \\
\underline{\text { instituto-do-patrimonio-historico-e-artistico-nacional-148- }} \\
\underline{\text { vagas }}\end{array}$ \\
\hline 2009 & 8 & Efetivo & http://portal.iphan.gov.br/editais/detalhes/26 \\
\hline 2013 & 80 & Temporário & $\underline{\text { http://portal.iphan.gov.br/editais/detalhes/27 }}$ \\
\hline 2015 & 48 & Temporário & $\begin{array}{l}\text { http://portal.iphan.gov.br/editais/detalhes/13/processo- } \\
\text { seletivo-simplificado-2015 }\end{array}$ \\
\hline 2018 & 47 & Efetivo & $\begin{array}{l}\text { http://portal.iphan.gov.br/editais/detalhes/266/concurso- } \\
\text { iphan-2018 }\end{array}$ \\
\hline Total & 205 & & \\
\hline
\end{tabular}

Em 2005, houve o primeiro concurso para servidores do quadro permanente do IPHAN, abrindo 22 vagas para arqueologia. Depois foram realizados mais dois concursos para o preenchimento de vagas permanentes, incluindo arqueólogos, e dois para vagas temporárias. Foi também em 2005 que a primeira turma do Programa de Especialização em Patrimônio iniciou suas atividades no IPHAN, contando com 3 vagas para arqueologia.

\section{O PEP E O MESTRADO DO IPHAN COMO TERMÔMETRO DAS DEMANDAS INTERNAS}

Inicialmente, cabe reforçar que esses dois programas de pós-graduação do IPHAN a especialização e o mestrado profissional - não têm por objetivo formar arqueólogos, mas sim profissionais para a preservação do patrimônio cultural, nos quais se incluem os gestores do patrimônio arqueológico. Entretanto, isto não significa dizer que os egressos do curso não possam atuar como arqueólogos. De acordo com o enquadramento jurídico vigente (nomeadamente, a lei ํㅜㄴ.653/18 e a Portaria IPHAN ํㅜㄴ 317/19, que dispõe sobre as atividades específicas do campo profissional da Arqueologia), alguns deles - titulados antes ou depois da referida lei de regulamentação da profissão - podem ser reconhecidos enquanto tal, desde que tenham realizado pesquisa em Arqueologia e atividades previstas na portaria supracitada.

A produção de conhecimento e a instrumentalização para o uso dos procedimentos de valorização e proteção de bens culturais estão entre os objetivos centrais da formação pós-graduada oferecida pelo IPHAN. 
Conforme dito, uma de suas características importantes é o procedimento de composição das turmas a partir de vagas propostas pelas unidades do IPHAN. Após análise dessas propostas, sempre em quantidade maior do que as bolsas de estudos efetivamente disponibilizadas pela instituição nos editais, a Coordenação do programa busca compor turmas equilibradas e diversificadas, considerando aspectos como: a distribuição regional, as diferentes estruturas institucionais das unidades, a diversidade de práticas, objetos e problemas oferecidos pelas unidades e áreas de conhecimento dos cursos de graduação.

Após essa análise e da decisão sobre os perfis das vagas de bolsa, são lançados editais públicos com os procedimentos de seleção. Para os alunos servidores públicos, tanto do IPHAN quanto os de outras instituições, que se candidatam sugerindo os próprios temas, são organizados editais específicos de seleção. Pode-se destacar que essa composição das turmas faz parte da proposta pedagógica da pós-graduação, destacandose as trocas disciplinares entre os participantes, discentes e docentes, principalmente durante os módulos de aulas.

Nos editais dos dois programas, seja o antigo de Especialização e o atual de Mestrado, observa-se um número significativo de pedidos de vagas de bolsistas para atuarem em práticas e desenvolverem temas relacionados ao patrimônio arqueológico. Entre esses pedidos, as vagas oferecidas se dividem entre aquelas que especificavam a necessidade de formação em Arqueologia ou em Arqueologia ou áreas afins, e aquelas que não especificavam a área de Arqueologia, conforme Tabela 1, a seguir. 
Tabela 1. Vagas oferecidas nos programas de pós-graduação do IPHAN

\begin{tabular}{|c|c|c|c|}
\hline $\begin{array}{l}\text { Ano do } \\
\text { pedido }\end{array}$ & $\begin{array}{l}\text { № de pedidos de } \\
\text { Arqueologia e } \\
\text { áreas afins }\end{array}$ & $\begin{array}{l}\text { № de pedidos sem } \\
\text { graduação em } \\
\text { Arqueologia }\end{array}$ & Total de solicitações \\
\hline 2005 & 0 & 3 & 3 \\
\hline 2006 & 3 & 0 & 3 \\
\hline 2007 & 1 & 1 & 2 \\
\hline $2008^{\star}$ & 0 & 0 & 0 \\
\hline 2009 & 1 & 4 & 5 \\
\hline 2010 & 6 & 3 & 9 \\
\hline 2011 & 4 & 0 & 4 \\
\hline 2012 & 1 & 2 & 3 \\
\hline 2013 & 3 & 1 & 4 \\
\hline 2014 & 1 & 0 & 1 \\
\hline 2015 & 3 & 1 & 4 \\
\hline 2016 & 2 & 0 & 2 \\
\hline 2017 & 2 & 2 & 4 \\
\hline $2018^{\star \star}$ & 0 & 0 & 0 \\
\hline Total & 27 & 17 & 44 \\
\hline \multicolumn{4}{|c|}{$\begin{array}{l}\text { *Ano de organização para transição da Especialização para o Mestrado, quando não foi } \\
\text { lançado Edital. } \\
\text { ** Ano em que as bolsas de estudos do IPHAN foram reduzidas de } 20 \text { para } 10 \text { e não houve } \\
\text { proposta de servidor público para o tema da Arqueologia. }\end{array}$} \\
\hline
\end{tabular}

A Tabela acima é bastante sintomática no que diz respeito ao total das vagas oferecidas pelas unidades do IPHAN em relação ao patrimônio arqueológico, pois ao longo de $13 \operatorname{anos}^{12}$ dos referidos programas de formação foram solicitadas 44 vagas para atuar junto à essa categoria de bem cultural, cerca de $14 \%$ do total das vagas oferecidas, mesmo com a realização de 05 concursos para a contratação de arqueólogos permanentes e temporários. Pode-se ainda entender que se trata de demanda importante diante da tradição institucional de atuar em temas da Arquitetura e cidades, assim como o período que coincide com investimentos na estruturação da área do patrimônio imaterial.

Observar as demandas de atuação junto ao patrimônio arqueológico permite identificar não apenas a situação institucional diante da necessidade de salvaguarda e preservação do patrimônio arqueológico, mas também realizar uma análise contextual da situação da formação do profissional em Arqueologia para atuar na gestão desse patrimônio, frente ao mercado de trabalho e à economia nacional.

${ }^{12}$ Exclui-se desta contagem o ano de 2008 que não houve edital.

\begin{tabular}{|l|l|l|l|l|l|l|} 
(C) Rev. Arqueologia Pública & Campinas, SP & v.13 & n.2 & p.156 & 2019 & ISSN 2237-8294
\end{tabular} 
A estruturação tardia dos cursos de Arqueologia no Brasil, nos níveis de graduação ou pós-graduação, teve reflexo direto na constituição e perfil das turmas dos programas de formação do IPHAN, frente a uma demanda latente por profissionais para a gestão do patrimônio arqueológico. No período de análise dos dados dos programas do IPHAN, o Brasil já contava com, ao menos, 13 cursos de graduação em Arqueologia. A maioria abertos entre 2007 e 2009, como resultado do aumento das demandas de profissionais na Arqueologia preventiva ou de contrato. No nosso entender, foram demandas grandemente provocadas pelo aumento exponencial de licenciamentos para empreendimentos decorrente do aquecimento da economia, em especial a economia industrial, trazida com o Programa de Aceleração do Crescimento - PAC, criado em 2007, conforme podemos observar na linha de tendência de aumento tanto no licenciamento ambiental, quanto nos pedidos de autorização de pesquisa ${ }^{13}$.

Nos anos de 2009, 2010, 2011, 2013, 2015 e 2017, o Mestrado em Preservação do Patrimônio Cultural teve as maiores demandas por vagas de alunos que atuassem junto ao patrimônio arqueológico, através de pesquisa e proposição de ações, fato que deve ser observado a partir de um contexto mais amplo. Isso porque, de 2009 a 2011, observa-se o grande "up" de pedidos de emissão de licença no IBAMA (conforme Gráfico 2).

\section{IPHAN \\ Gráfico 2. Portarias de autorização de pesquisa emitidas pelo IBAMA e pelo}

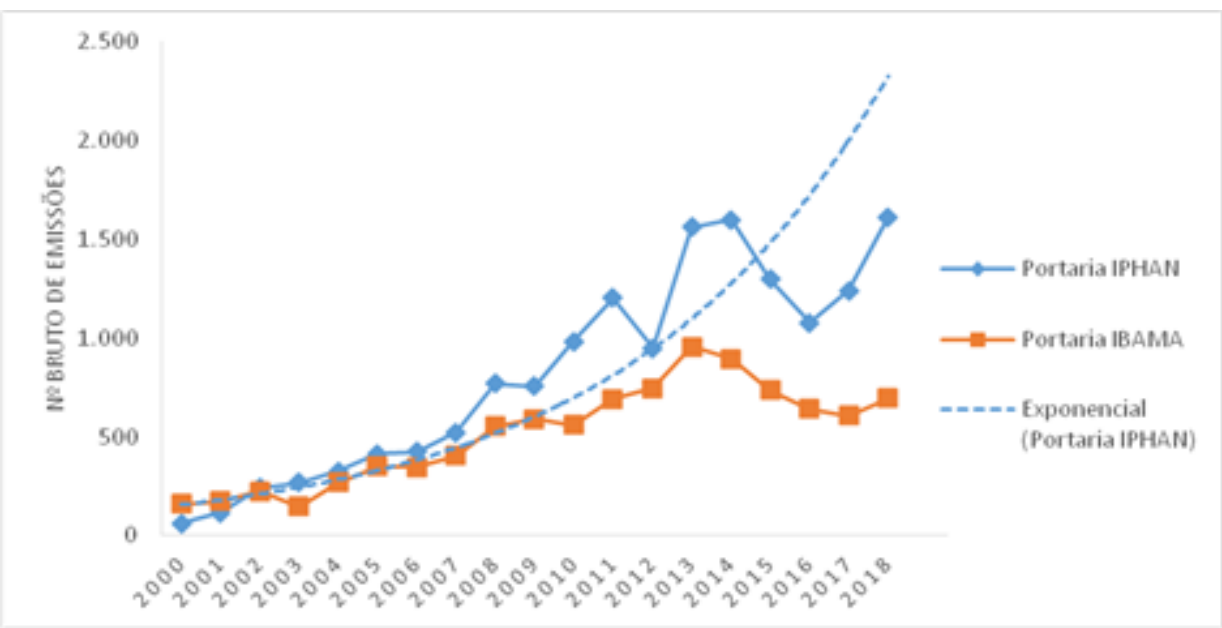

Fonte: IPHAN/2019 e IBAMA/2019

${ }^{13} \mathrm{~A}$ diferença no valor bruto dos dados se deve ao quantitativo de licenciamento patrimonial solicitado pelos estados, visto que o gráfico de licenciamento ambiental é referente apenas aos dados do IBAMA.

(C) Rev. Arqueologia Pública Campinas, SP

\begin{tabular}{l|l|l}
$\mathrm{v} .13$ & $\mathrm{n} .2$
\end{tabular}

p.157

2019 ISSN 2237-8294 
Nesse contexto, desde a criação do PEP em 2004, uma das mais importantes preocupações do formato pedagógico da pós-graduação do IPHAN foi encontrar um equilíbrio entre conteúdos relacionados às diversas disciplinas de interesse do campo de preservação do patrimônio cultual e as especificidades da formação dos alunos, de seus temas e objetos de interesse. Além do delicado equilíbrio das disciplinas, que se consolidou na opção de organizar conteúdos de curta duração, que tratassem de um leque de questões, se buscou a ênfase na formação mais focada em temas nas práticas profissionais, que se desenvolvem durante 30 horas semanais ao longo de 18 meses do curso. Nessas práticas, é exigida dos mestrandos a elaboração de três produtos ${ }^{14}$, a partir da experiência da imersão deste ao cotidiano da unidade, que são supervisionados e avaliados por técnicos do IPHAN, como parte da disciplina Práticas Supervisionadas I, II e III. As dissertações também promovem um enfoque sobre os temas de interesse das unidades do IPHAN e dos próprios alunos.

A vocação transdisciplinar do campo do patrimônio, no qual a Arqueologia está inserida, e a adequação dos tópicos específicos da Arqueologia às necessidades da pósgraduação proposta, podem ser constatadas tanto nos produtos gerados pelos alunos nas suas práticas profissionais durante o curso, quanto nas dissertações e tipos de abordagem produzidas sobre o patrimônio arqueológico por graduados de diferentes áreas. Para se ter uma ideia, foram desenvolvidos temas como a socialização de sítios arqueológicos, a educação para preservação desses sítios, a conservação de materiais em locais de guarda, o acompanhamento e fiscalização desses locais, seu mapeamento territorial, o cadastramento informatizado, a reparação de danos a sítios arqueológicos, os diferentes significados sociais atribuídos aos sítios pelas populações das localidades, entre outros. Esses temas foram desenvolvidos por alunos graduados em diferentes áreas de conhecimento, tais como: Arqueologia, História, Geografia, Educação e Gestão Territorial Indígena ${ }^{15}$.

Observa-se nos trabalhos desenvolvidos a construção de um olhar de gestor, que independentemente da área específica de graduação do aluno, apresenta uma 14 Os títulos dos produtos podem ser consultados através do portal IPHAN e no Arquivo central do
IPHAN - Seção Rio de Janeiro <http://portal.iphan.gov.br/pep/pagina/detalhes/1963>

${ }^{15}$ As dissertações do Mestrado Profissional do IPHAN estão disponíveis no Portal da instituição e as monografias produzidas no Programa de Especialização estão em parte publicadas (ver http://portal.iphan.gov.br/pep/pagina/detalhes/308) e em parte estão no Arquivo central do IPHAN Seção Rio de Janeiro. 
sensibilidade para as diversas questões sociais, históricas, jurídicas e tecnológicas envolvidas na preservação de bens arqueológicos. Por outro lado, encontrar um equilíbrio nas disciplinas que organizam os conteúdos tratados junto com os alunos, vem demonstrando o respeito às questões arqueológicas em trabalhos relacionados a outros bens e temas da preservação do patrimônio cultural. Esta é uma contribuição para o tratamento desse tipo de patrimônio específico e complexo da disciplina obrigatória "Patrimônio Arqueológico: legislação e pesquisa", sobre a qual refletiremos a seguir, considerando os desafios de ordem conceitual e metodológica para adequá-la ao corpo discente do Mestrado.

\section{ENTRE DESEJO E REALIDADE: ENQUADRAMENTOS TEÓRICOS E METODOLÓGICOS DA DISCIPLINA "PATRIMÔNIO ARQUEOLÓGICO: LEGISLAÇÃO E PESQUISA"}

Desde o seu formato inicial, o Mestrado Profissional do IPHAN apresenta em seu projeto pedagógico a cadeira "Patrimônio Arqueológico: legislação e pesquisa", com caráter obrigatório perante a CAPES. O objetivo principal dessa disciplina é apresentar, numa perspectiva panorâmica: as principais legislações aplicadas na preservação do patrimônio arqueológico nas etapas de licenciamento patrimonial, as principais questões e teorias que constituem o campo da Arqueologia; as relações entre a Arqueologia e outros campos do conhecimento; a ética e o profissional arqueólogo como pesquisador, gestor ou professor; a Arqueologia no pensamento preservacionista e a sua atuação no IPHAN; algumas cartas patrimoniais com foco no patrimônio arqueológico; as intervenções em sítios e coleções arqueológicas; e, por fim, aspectos da Arqueologia Sensível, relacionadas às comunidades indígenas e tradicionais.

A exposição do conjunto de objetivos não deixa sombra de dúvidas de que, apesar da estratégia de apresentar os conteúdos de uma forma panorâmica (única alternativa viável, tendo em vista não somente a variedade de tópicos, mas, também, a carga horária da disciplina, de 15 horas, e a heterogeneidade do corpo discente, graduado nas mais diversas áreas) é grande o desafio de delinear um enquadramento teórico e metodológico coerente e consoante com a finalidade da cadeira e do programa interdisciplinar. Cabe lembrar a vastidão e complexidade do conteúdo programático da Arqueologia enquanto campo de pesquisa e, igualmente, da gestão do patrimônio arqueológico, diferenciado pela 
sua condição de bem da União (de acordo com o Art. 20 da CF/1988) acautelado, cadastrado ou não, pela Lei no $3.924 / 61$.

Além disso, é importante ressaltar, embora as produções acadêmicas sobre temas relacionados à gestão do patrimônio arqueológico venham aumentando expressivamente ${ }^{16}$, dentre as quais destacamos a dissertação de mestrado de Maria Lúcia Pardi (2002), que busca abordar aspectos da gestão do patrimônio arqueológico, mais especificamente das informações sobre o patrimônio arqueológico, ainda carecemos de referências mais sistematizadas e em língua portuguesa. Assim sendo, para fundamentar os conteúdos da cadeira, recorremos a obras dedicadas à gestão do patrimônio cultural numa perspectiva mais geral, de autores como Freeman Tilden (1977), María Ángeles Querol (2008) e Marta Martos Molina (2016).

Outro desafio incontornável refere-se à heterogeneidade do corpo discente, no que diz respeito à formação (ainda que majoritariamente das áreas das Humanidades e Ciências Sociais), à atuação e à experiência profissional. $E$ há ainda o desafio que se configura quanto ao lugar de fala, seja dos docentes do programa ou dos discentes, dentro de um programa oferecido pela instituição responsável pelas políticas públicas direcionadas à salvaguarda e preservação do patrimônio, com uma visão ampla do perfil da gestão do patrimônio arqueológico.

Diante disso, os discentes da cadeira, tiveram como preocupação definir critérios para seleção dos pontos do conteúdo programático e também justificá-los com argumentos claros e coerentes em relação aos princípios/premissas e objetivos da mesma. Assim sendo, ainda que guardando fidelidade à ementa da disciplina, foram enfatizados alguns pontos e utilizados métodos e dinâmicas variadas com vistas a atender às especificidades do público-alvo e, assim, tornar mais claro e digerível o conteúdo se, porventura, este não estiver muito afeito e a par do tema tratado pela disciplina. Sobretudo, busca-se atender à demanda de profissionais com perfis transdisciplinares para atuar na gestão do patrimônio cultural, incluindo os bens arqueológicos.

\footnotetext{
16 Grasiela Tebaldi Toledo (2017) apresenta, em sua tese de Doutorado em Arqueologia, um consistente levantamento bibliográfico da produção acadêmica dedicada à preservação do patrimônio arqueológico (enfatizando os aspectos relacionados à musealização, à educação patrimonial e à conservação, dentre outros assuntos), a iniciar ainda na década de 1980, com a dissertação de Cristina Bruno (1984) e a findar com os estudos apresentados em 2017.
} 
Os princípios/premissas básicas da cadeira foram identificados a partir da reflexão e discussão sobre alguns questionamentos incontornáveis:

1) O que se espera de um gestor do patrimônio cultural no que se refere à preservação do patrimônio arqueológico?

2) Que conteúdos e aspectos da Arqueologia são imprescindíveis de serem trabalhados no sentido de desmistificar essa disciplina, bem como a atuação do seu profissional, problematizando noções do senso comum?

3) Que conteúdos e aspectos da gestão do patrimônio arqueológico são importantes de serem trabalhados para compreender o contexto, em especial, o enquadramento jurídico, as dinâmicas e instrumentos aplicados?

4) Que conteúdos e aspectos da Arqueologia Brasileira são necessários para compreender o estado da arte da produção de conhecimento?

Por sua vez, todas as questões supracitadas conduziram-nos para a questão principal, a saber: o que é a gestão do patrimônio arqueológico?

Por gestão, lançando mão da literatura da Administração, compreendeu-se a gestão como uma atividade que necessita de um conjunto de habilidades técnicas e relacionais, para que se atinja as metas de acordo com o objetivo da organização mesmo que as pessoas e coisas a serem administradas tenham perspectivas e objetivos pessoais divergentes ${ }^{17}$. E, no campo do patrimônio cultural, encontra-se no Conselho Internacional de Monumentos e Sítios (ICOMOS), as bases conceituais para a gestão do patrimônio arqueológico, sintetizadas na proteção e administração dessa categoria de bem em seu contexto e respeitando suas relações com a História e a sociedade contemporânea.

Entretanto, as bases para identificar e compreender as especificidades e complexidades da gestão do patrimônio arqueológico enquanto conceito e ação, teve base no estudo de Maria Lúcia Pardi (2002) e no Programa Intermediário de Gestão do Patrimônio Arqueológico, a primeira proposta sistematizada pelo Centro Nacional de Arqueologia/IPHAN. Mais recentemente, deve-se ter como base a Portaria n. 375/18, que dispõe sobre a Política de Patrimônio Cultural Material e contribui para o entendimento do conceito de gestão do patrimônio cultural para o IPHAN como parte de cada ação e atividade relacionada com a preservação do patrimônio cultural material. A portaria traz

17 Definição encontrada no Guia de Gerenciamento no Setor Público - Serge Alecian \& Dominique Foucher - Ed. Revan Ltda - ENAP 2001.

(C) Rev. Arqueologia Pública Campinas, SP v.13 n.2 p.161 2019 ISSN 2237-8294 
ainda aspectos sobre o planejamento e implementação de estratégias e práticas a serem consideradas em todos os processos relativos à preservação e à administração do patrimônio arqueológico.

Assim, foram identificadas e selecionadas as premissas/princípios para a conformação do conteúdo programático a partir de diversos autores e experiências adquiridas desde que assumimos a cadeira.

No que confere à importância da disciplina dentro de um contexto mais amplo na formação do gestor do patrimônio cultural, deve-se concordar com Lindskough (2019), para quem a Arqueologia "traz para a memória uma perspectiva de longa duração, política, social, ecológica e cultural", sendo a arqueologia uma disciplina essencialmente interdisciplinar, polifônica e multivocal no que se refere ao objeto de estudo, à perspectiva teórica e às linhas de pesquisa.

Cabe, dentro dos princípios, apresentar autores como Bruce Trigger (2004), Thomas e (2004) e Harrison (2013), para quem a Arqueologia, como disciplina, é fruto da "modernidade, com raízes nacionalistas e colonialistas e intimamente ligada ao patrimônio e aos museus pelas suas práticas colecionistas" (LINDSKOUGH, 2019: 14);

No âmbito do pensamento na Arqueologia brasileira, são referência autores (PROUS, 1992; FUNARI, 2003; LIMA, 2011) que tratam a Arqueologia como um campo produtor de narrativas sobre processos históricos e comportamentais sobre sociedades do passado a partir da referente materialidade e da integração da forma, do espaço e do tempo (esta última variável sem, a princípio, qualquer limitação). Tal abordagem permite ampliar as noções pré-estabelecidas sobre o campo de atuação da Arqueologia.

Sem a remota pretensão de tratar em profundidade nem a polifonia teórica da Arqueologia, nem a complexidade da gestão do patrimônio arqueológico em sua inteireza, visto que a realidade anteriormente citada não permitiria, alguns tópicos podem ser destacados, a partir de exemplos e estudos de caso, dentre os quais: 
- A prática arqueológica, que vai muito além da etapa de campo e não se restringe à escavação ou outra técnica interventiva da matriz arqueológica ${ }^{18}$;

- A atuação da/do arqueóloga/o, e decorrente produção de conhecimento, que são conformadas/constrangidas por pressões endógenas e exógenas ao campo;

- A rigor, no que concerne à elaboração e desenvolvimento do projeto de pesquisa (fundamentação teórica e rigor metodológico, que resultam na produção de dados e interpretações sobre os objetos estudados e decorrentes fontes de novas pesquisas), não há, ou deveria haver, diferença entre a Arqueologia desenvolvida no âmbito das instituições científicas e a Arqueologia vinculada a empreendimentos públicos e/ou privados;

- A conjuntura atual exige ética profissional e atuação para a sociedade (no que se refere à preservação do patrimônio arqueológico ou ao compromisso com o bemestar e justiça social);

- A gestão do patrimônio arqueológico se manifesta em políticas públicas claras (enquadramento jurídico-legal, princípios e fundamentos, instrumentos específicos, plano de ação definido);

- A ideia de estratigrafia do abandono (BRUNO, 2005) é imperativa para compreender o estado da arte da gestão do patrimônio arqueológico;

- A socialização do patrimônio arqueológico é a finalidade da gestão do patrimônio arqueológico' ${ }^{19}$;

- A Musealização da Arqueologia é uma linha de pesquisa fundamental para as boas práticas sobre o patrimônio arqueológico, promovendo o debate sobre a "razão póscolonial e a reprodução da violência epistêmica" (LINDSKOUGH, 8: 2019).

- Os estudos, articulações e militância dos agentes envolvidos com a preservação do patrimônio arqueológico, em articulações e movimentos sinérgicos com as instituições do patrimônio (designadamente o Instituto do Patrimônio Histórico e Artístico Nacional e o Instituto Brasileiro de Museus) contribuem para a gestão do patrimônio arqueológico pautada na ideia de "boas práticas"20.

$18 \mathrm{O}$ debate sobre tal aspecto não prescinde da Lei n. $13.653 / 18$, que regulamenta a profissão de arqueólogo, bem como o Código de Ética da Sociedade de Arqueologia Brasileira.

19 No âmbito do IPHAN, premissa se consolida no Plano Intermediário de Gestão do Patrimônio Arqueológico (2011).

20 O conceito de "boas práticas", largamente utilizado nas mais diversas áreas, no campo do patrimônio cultural pode ser compreendido de formas diversas. No que se refere concretamente à gestão de bens culturais, as boas práticas baseiam-se em processos participativos desenvolvidos por meio de uma metodologia dividida em três etapas complementares. A primeira refere-se aos estudos

\begin{tabular}{|l|l|l|l|l|l|l|}
\hline (c) Rev. Arqueologia Pública & Campinas, SP & v.13 & n.2 & p.163 & 2019 & ISSN 2237-8294 \\
\hline
\end{tabular}


A perspectiva teórica que ancora a abordagem, a exposição e o debate sobre o conteúdo programático encontra-se no Institucionalismo Histórico (SALADINO, 2010). Cabe ressaltar que essa corrente do Neoinstitucionalismo, a partir da qual compreende-se o conceito instituição como o conjunto complexo de convenções, normas, enquadramentos e dispositivos legais, além da mais variada gama de agentes sociais, atuando nos campos político, econômico, jurídico-legal e social possibilitam compreender os valores, intenções, escolhas e padrões institucionais que fundamentam, conformam e conduzem a dinâmica da gestão do patrimônio cultural. Isso vai ao encontro de um dos princípios da Política de Patrimônio Cultural Material do IPHAN, mais precisamente do princípio da atuação em rede, no sentido de que a gestão se dá na articulação entre "instituições, públicas e privadas, sociedade organizada e profissionais da área de preservação".

Com a transformação do Programa de Especialização do IPHAN para a modalidade mestrado profissional, a disciplina em tela passou a ser oferecida por duas professoras, com atuação e expertise na área técnica e na acadêmica. De início, as metodologias e os recursos de ensino centravam-se em aulas expositivas e visitas técnicas. Com o passar do tempo, considerando as avaliações e provocações do corpo discente e graças ao investimento em capacitação por parte do IPHAN e por parte das próprias docentes, as aulas passaram a ser expositivo-participativas, com a incorporação de outros métodos, como a metodologia da cooperação, e ferramentas como a "tempestade de ideias", "world café" e o "aquário". A mudança nas metodologias deveu-se à necessidade de tornar os conteúdos mais acessíveis e interessantes ao corpo discente do qual, como anteriormente exposto, apenas uma pequena parcela dedica sua pós-graduação à gestão do patrimônio arqueológico, mas todos precisam ter conhecimento sobre a idiossincrasias desse. Além disso, tencionava-se estimular o pensamento crítico de acordo com um processo de intercâmbio de conhecimentos e experiências entre docente e discentes, procurando o estabelecimento de uma relação de reciprocidade de aprendizagem. Destarte, diversos recursos são experimentados e utilizados, dentre os quais a exibição de filmes e documentários, visitas técnicas e rodas de conversa. A título de ilustração, pode-se destacar as videoconferências realizadas em setembro de 2019, com a Profa. Dra. Alicia Castillo Mena, da Universidade Complutense de Madrid e Presidenta do ICOMOS-Espanha 
e a Profa Dra. Alice Semedo, da Universidade de Porto, centradas sobre o tema da gestão do patrimônio sensível.

\section{NOTAS FINAIS}

A análise dos dados referentes às solicitações enviadas ao Mestrado Profissional do IPHAN pelos distintos setores que compõem o IPHAN, à luz das premissas e perspectivas sobre as especificidades do patrimônio arqueológico e da própria gestão do patrimônio cultural indicam o desafio imposto aos agentes dedicados ao tema e, consequentemente, a complexidade de delinear uma formação básica.

Partindo do pressuposto de que o patrimônio cultural é, idealmente, um campo transdisciplinar, e considerando que a gestão de patrimônio não é assunto prioritário na formação em Arqueologia (nem em qualquer das disciplinas que constituem a "Ciência do Patrimônio"21) e o disposto na Portaria n.375/18 (basicamente, o princípio da atuação em rede e a gestão compartilhada), que, cabe lembrar, vai ao encontro do Art. 216 da Constituição de 1988, entende-se não haver, a princípio, restrição para participar dessa ação. Os dados sobre o corpo discente dedicado ao tema demonstram isso. Afinal, os estudos sobre as diversas atividades que constituem a gestão do patrimônio arqueológico foram desenvolvidos por profissionais oriundos de diversos campos, como a História, Direito, Arquitetura, Geografia, Antropologia, entre outros.

A complexidade da preservação do patrimônio arqueológico (resultante do entrelaçamento das políticas de patrimônio, de formação e pesquisa e, ainda, de desenvolvimento econômico) impõe ao IPHAN desafios decorrentes das escolhas institucionais que levaram à sua tardia estruturação para lidar com a estratigrafia do abandono (cabe lembrar que o Centro Nacional de Arqueologia foi criado em 2009 e, antes disso, eram escassos e insuficientes seus recursos financeiros e humanos direcionados para o patrimônio arqueológico). Nesse sentido, a pós-graduação do IPHAN, nos seus treze anos de atuação, procura atender às necessidades da autarquia, lançando mão de recortes

${ }^{21}$ Ciência do Patrimônio é um termo que representa o campo transdisciplinar constituído pelas ciências humanas e naturais, destacando-se a Ciência da Conservação, a Ciência Arqueológica e a Ciência do Restauro (STRLIČ, 2018), contemplando "aspectos físicos e materiais que dão suporte à Conservação-Restauração, mas também à gestão, registro, documentação e interpretação do patrimônio cultural" (BARROS, 2019).

\begin{tabular}{|l|l|l|l|l|l|l|l|}
\hline (C) Rev. Arqueologia Pública & Campinas, SP & v.13 & n.2 & p.165 & 2019 & ISSN $2237-8294$ \\
\hline
\end{tabular}


teóricos e de técnicas que não escamoteiem os desafios, idiossincrasias e tensões que constituem a gestão do patrimônio arqueológico.

O programa de pós-graduação do IPHAN - desde a especialização até o mestrado vem assim, como um termômetro da relação entre a instituição e o patrimônio arqueológico, demonstrar a importância de compreender o caráter transdisciplinar da gestão desse patrimônio e a necessidade de se criar estratégias de formação que assumam as especificidades desta área de proteção e salvaguarda do patrimônio arqueológico.

\section{REFERÊNCIAS}

ALECIAN, Serge; FOUCHER, Dominique. Guia de Gerenciamento no Setor Público. Rio de Janeiro: Editora Revan, 2001.

BEZERRA, Marcia. Bicho de nove cabeças: os cursos de graduação e a formação de arqueólogos no Brasil. Revista de Arqueologia, v.21.2, p.139-154, 2008.

BRUNO, Maria Cristina de Oliveira. O Museu do Instituto de Pré-História: um museu a serviço da pesquisa científica. Dissertação de Mestrado em História Social. Universidade de São Paulo, 1984.

. Arqueologia a antropofagia: a musealização de sítios arqueológicos. Revista do Patrimônio Histórico e Artístico Nacional, no 31, 2005, p. 234-247. $<$ http://portal.iphan.gov.br/uploads/publicacao/RevPat31 m.pdf > [Acesso em 17 de Janeiro de 2020]

. Museus de Arqueologia no Brasil: uma estratigrafia de abandonos e de desafios. BRAGA, Eneida; COSTA, Ana Lourdes de Aguiar (orgs.) Anais 200 anos de museus no Brasil: desafios e perspectivas. Brasília: IBRAM, 2018. < https://www.museus.gov.br/wp-content/uploads/2019/08/Anais-

200anosMuseusBrasil FINAL.pdf > [Acesso em 10 de outubro de 2019]

CASTILLO MENA, Alicia; DOMINGUEZ, Marta; SALTO-WEISS; Isabel (2014), "Citinzenship and Heritage Commitment: Looking for Participatory Methodologies Adopted to the Urban Cultural Heritage Context". DI STEFANO, Maurizio (org.), $18^{\text {th }}$ ICOMOS General Assembly - Conference Proceedings. Charenton-le-Pont/Firenze: ICOMOS/Edizioni Scientifiche Italiane, 415-421.

CHUVA, Marcia. Fundando a nação: a representação de um Brasil barroco, modernos e civilizado. Topoi, 4(7):313 - 333, 2003.

FUNARI, Pedro Paulo. Arqueologia. São Paulo: Contexto, 2003.

FUNARI, P. P. A Arqueologia no Brasil e no mundo: origens, problemáticas e tendências. Ciência e Cultura. São Paulo, v. 65, n. 2, p. 23-25, 2013.

GONÇALVES, Wille de Barros. Ciência do Patrimônio. Associação Nacional de Pesquisa em Tecnologia e Ciência do Patrimônio. <

\begin{tabular}{|l|l|l|l|l|l|l|}
\hline (C) Rev. Arqueologia Pública & Campinas, SP & v.13 & n.2 & p.166 & 2019 & ISSN 2237-8294 \\
\hline
\end{tabular}


http://lacicor.eba.ufmg.br/antecipa/index.php/ciencia-do-patrimonio/ > [Acesso em 20 de outubro de 2019]

GONÇALVES, José Reginaldo Santos. O patrimônio como categoria de pensamento. In. ABREU, Regina; CHAGAS, Mário (orgs.). Memória e patrimônio: ensaios contemporâneos. $2^{a}$ ed. Rio de Janeiro: Lamparina, pp.25-33, 2009.

HARRISON, Rodney. Heritage. Critical Approaches. New York: Routledge, 2013. IPHAN. Plano Intermediário para Gestão do Patrimônio Arqueológico. Brasília: IPHAN, 2011.

LIMA, Tania Andrade. Cultura material: a dimensão concreta das relações sociais. Boletim do Museu Paraense Emilio Goeldi, v.6, n.1, p.11-23, jan-abr.2011. < http://www.scielo.br/pdf/bgoeldi/v6n1/a02v6n1 > [Acesso em 20 de julho de 2019]

LINDSKOUGH, Henrik B. "Coleccionando naturaleza, creando cultura: construcción de la docotomía naturaliza/cultura en museos. Antípoda. Revista de Antropología y Arqueología, n. 36, Bogotá, julio-septiembre, 2019, p.11-32. < https://issuu.com/publicacionesfaciso/docs/revista antipoda no. $36>$ [Acesso em 20 de julho de 2019]

MOLINA, Marta Martos. Herramientas para la gestión turística del patrimônio cultural. Gijón: Ediciones Trea, 2016.

PARDI, Maria Lúcia Franco. Gestão de Patrimônio Arqueológico, Documentação e Política de Preservação. Mestrado Profissionalizante em Gestão do Patrimônio Cultural. Goiânia: Instituto Goiano de Pré-História e Antropologia, 2002.

PROUS, André. Arqueologia Brasileira. Brasília: EDUNB, 1992.

QUEROL, María Ángeles. Manual para la gestión del patrimonio cultural. Madrid: Akal, 2008.

SALADINO, Alejandra. Prospecções: o patrimônio arqueológico nas práticas e trajetória do IPHAN. Tese de Doutorado em Ciências Sociais. Universidade do Estado do Rio de Janeiro, 2010.

SILVA, Regina Coeli Pinheiro. Compatibilizando os instrumentos legais de preservação arqueológica no Brasil: o Decreto-Lei ํㅡ 25/37 e a lei no 3.924/61. Revista de Arqueologia, 9:9-23,1996.

STANCHI, Roberto. O patrimônio arqueológico: oitenta anos de delegações. Revista do Patrimônio Histórico e Artístico Nacional, n.35, 2017, p. 171-202 < http://portal.iphan.gov.br/uploads/publicacao/revpat 35.pdf $>$ [Acesso em 21 de julho de 2017]

STRLIČ, Matijia. Angewandte Journal, 57, 2018, p. 2-4. < http://www.e-rihs.eu/prof-strlicintroduces-heritage-science-means/ $>$ [Acesso em 20 de outubro de 2019]

TILDEN, Freeman. Interpreting our heritage. North Carolina: University of North Carolina Press, 1977. 
TOLEDO, Grasiela Tebaldi. Musealização da Arquelogia e Conservação Arqueológica: experiências e perspectivas para a preservação patrimonial. Tese de Doutorado em Arqueologia. Universidade de São Paulo, 2017.

TRIGGER, Bruce. História do Pensamento Arqueológico. São Paulo, 2004.

VIANA, Sibeli; BEZERRA, Marcia, EREMITES, Jorge (orgs.). Revista Habitus, 2015.

\section{OUTRAS FONTES}

BRASIL. Constituição Federal (1988). Seção II, Artigo 216. Disponível em: https://www.senado.leg.br/atividade/const/con1988/CON1988_05.10.1988/art_216_.asp. [Acesso em 19 de janeiro de 2020.]

BRASIL. Decreto-Lei no 25/1937. Disponível em:

http://www.planalto.gov.br/ccivil 03/decreto-lei/del0025.htm [Acesso em 19 de janeiro de 2020.]

BRASIL. Lei no 13.653/18 . Disponível em: https://www2.camara.leg.br/legin/fed/lei/2018/lei13653-18-abril-2018-786578-publicacaooriginal-155382-pl.html [Acesso em 17 de Janeiro de 2020]

BRASIL. PAC. (site) 2007. Disponível em: http://pac.gov.br/. Acesso em:19 jan.2020. ICOMOS. Charte internationale pour la gestion du Patrimoine archeologique.1990. Disponível em: https://www.icomos.org/charters/arch f.pdf [Acesso em 19 de janeiro de 2020.]

IPHAN. Portaria IPHAN no 317/19 < https://www.legisweb.com.br/legislacao/?id=384383 > [Acesso em 17 de Janeiro de 2020]

IPHAN. Portarias de pesquisas arqueológicas publicadas no DOU - 1991 a 2020. < http://portal.jphan.gov.br/cna/pagina/detalhes/1375/> [Acesso em 19 de novembro de 2019]

IBAMA. Consulta de licencias por ano.

$<$ https://servicos.ibama.gov.br/licenciamento/consulta rel licencia por ano.php> [Acesso em 19 de novembro de 2019]

Recebido em: 31/10/2019

Publicado em: 15/02/2020 